\title{
Norway's gender gap: classroom participation in undergraduate introductory science
}

\author{
Cissy Ballen ${ }^{1,2}$, Marie Danielsen ${ }^{3}$, Christian Jørgensen ${ }^{3}$, John-Arvid Grytnes ${ }^{3}$, and Sehoya Cotner ${ }^{1,4}$ \\ ${ }^{I}$ Department of Biology Teaching and Learning, University of Minnesota, Minneapolis, MN, USA \\ ${ }^{2}$ E-mail: balle027@umn.edu \\ ${ }^{3}$ Department of Biology, University of Bergen, Bergen, Norway \\ ${ }^{4}$ BioCEED Centre of Excellence in Biology Education
}

\begin{abstract}
To assess the extent that gender disparities exist at the undergraduate level in STEM, we analyzed participation in three large introductory biology classes in Norway, a country with one of the highest ratings of gender equality in the world. Biology 100 is a traditionally taught lecture course for first year students that has one instructor, and employs diverse pedagogical techniques to increase engagement. Biology $102 \mathrm{~A}$ and $102 \mathrm{~B}$ are two immersive field courses for second year students; classes often take place in atypical teaching venues both indoors and outside. In Biology 100 and Biology 102B, we discovered that women participate less than would be expected given their numerical dominance, matching results from similar research conducted in the United States. In Biology $102 \mathrm{~A}$ women participate the amount that would be expected given their numbers, and in no instances did we observe women speaking significantly more than would be expected. We discuss our results in the context of female success in STEM. If gender gaps in participation and performance are mutually reinforcing, educators seeking to promote women should address both factors simultaneously to maximize student achievement. Effective interventions are of critical importance for women in science, and have strong implications for the achievement of equity in STEM disciplines.
\end{abstract}

Keywords: Biology; gender; participation; STEM equity

\section{INTRODUCTION}

Gender differences in performance and perceptions within STEM continue to be widespread globally, influencing the retention and success of women across disciplines. Increasing evidence suggests social conditioning and 'chilly' classroom environments have a larger influence on women than do traditional biologically-based explanations, which hold little support (1-3). Still others point to 'a lack of enlightened policies' and gender-equal cultures contributing to the gender gap (4-6). In the United States, where the majority of STEM equity research has occurred, women enter STEM fields as undergraduates with lower academic confidence $(7,8)$, weaker identities as scientists $(9-12)$, and generally, lower numeric representation in the classroom $(13,14)$. At the undergraduate level, measures of success typically include grades and retention within STEM majors. Another measure worthy of attention is in-class participation, because students who participate in lecture exert an influence on their peers, and communicate their understanding of class materials $(15,16)$. Throughout the undergraduate experience, women in STEM are more likely to face subtle bias from their peers and faculty that may have lasting negative impacts on academic performance and measures of active inclass participation (15-17). The outcome is female attrition along the STEM pathway, such that at the faculty level, only one third across geoscience and life science disciplines are women (18). This further disadvantages female undergraduates, who disproportionately benefit by having women in positions of authority within their discipline; female faculty are more likely to serve as mentors for women (19), and their presence increases female students' confidence in their ability to do science (7), science identities (20), and their performance (21-24) and persistence (25) in STEM.

It is commonly assumed that biology does not suffer from the same gender gap as other maledominated STEM disciplines because women consist of approximately $60 \%$ of all undergraduate biology students $(26,27)$. However, the clear decline in the proportion of women at postgraduate levels suggest otherwise, with men outnumbering women at the postdoctoral level and even fewer women obtaining faculty positions or STEM jobs relative to males $(28,29)$. 
Recent research points to the possibility that increasing domestic gender equality may reduce or ameliorate the STEM gender gap: one international study involving more than half a million participants showed the gender gap in science and math was more pronounced in countries that scored higher in an Implicit Bias Test, which evaluates the extent that people associate science with males more than with females (6). Thus, we questioned whether the gender differences documented in the United States would also be present in large universities located in more gender-equal nations. The World Economic Forum (2015) lists Norway as a global leader in gender equity according to indices including equal pay for women, access to education, and political representation in parliament. However, even in Norway, women decline in representation at the faculty level in biological disciplines (30). Do women in undergraduate biology in Norway face the same inequities as women elsewhere that lead to the decision to leave the field? We explore one of the ways in which this may begin to manifest at University of Bergen: whole-class participation in large, lower-division biology courses. To test this question, we document classroom behaviors of men and women across different biology courses in Fall 2016 using a protocol that characterized 7 different types of in-class participation.

\section{METHODS}

\subsection{Classroom observations}

Our observation protocol characterized classroom participation by quantifying types of interactions that occurred over an approximately 50-minute class period, and noting the gender of students who participated. Observers sat at the back row and were indistinguishable from an ordinary student. If observers detected any ambiguity with respect to student gender identity, they asked the instructor for clarification. We acknowledge that gender is a fluid, complex identity and that some individuals do not identify with being either male or female, and others identify as a blend of both. However, because binary gender identity is still a predictor of disparities in STEM, for the purposes of the current study we identify students as either male or female. Biology 100 was taught by a male instructor, and both men and women taught both sections of Biology 102. For the analyses, we combined interactions into two categories following the statistical methods of Eddy et al. (24): 1) asking a spontaneous question or making a comment and 2) volunteering an answer following an instructor-generated question (Table 1). For example, 'Spontaneous' includes classroom interactions that are described as 'individual spontaneous comment or question' and 'spontaneous call post-Think Pair Share'. Similarly, 'Volunteer' includes classroom interactions that are described as 'individual volunteer response', 'volunteer response post-Think Pair Share', and 'volunteer response post-Think Pair Share and iclicker'. We only included instructors who had a total of five or more students interact in any of the polled categories across a minimum of three observed class sessions. This led to the exclusion of one interaction category for Biology 102B. Two different research assistants observed the three classes, and were prior to data collection trained in the protocol we developed for this study by talking through each category followed by watching lectures online and reaching a consensus on how to bin each interaction. The two research assistants then observed two 50 minute classes together in order to test for inter-rater reliability. Observers demonstrated identical observation records after comparing data from those classes.

\section{Student population}

University of Bergen (UiB) is a public university located in Bergen, Norway. Our study focused on two lower division biology courses that are required of all biology majors and attended primarily by students in their first (Biology 100: Introduction to Evolution and Ecology) or second (Biology 102: Organismal biology) year at UiB. In Fall 2016, Biology 100 took place on campus in a traditional lecture hall. The gender composition of Biology 100 was $58 \%$ female $(\mathrm{N}=177)$. Biology 102 is a field course that took place at The Heathland Centre at Lygra, an island off the west coast of Norway. Due to logistical and housing constraints, approximately half of the class (Biology 102A; 47\% female; $\mathrm{N}=$ 46) attended the field course during the first week and the other half of the class (Biology 102B; 61\% female; $\mathrm{N}=44$ ) attended the field course during the second week. 
Nordic Journal of STEM Education, Vol. 1, No. 1 (2017), pp 262-270.

\begin{tabular}{|l|l|l|}
\hline $\begin{array}{l}\text { Pooled } \\
\text { category name }\end{array}$ & $\begin{array}{l}\text { Scored in-class } \\
\text { interaction }\end{array}$ & Description of student-instructor interaction \\
\hline \multirow{5}{*}{$\begin{array}{l}\text { Spontaneous } \\
\text { question or } \\
\text { comment } \\
\text { spontaneous } \\
\text { comment or } \\
\text { question }\end{array}$} & $\begin{array}{l}\text { An unprompted response. When a student makes a comment } \\
\text { or asks a question without being requested to do so by the } \\
\text { instructor. }\end{array}$ \\
\cline { 2 - 4 } & $\begin{array}{l}\text { Spontaneous call } \\
\text { post-Think Pair } \\
\text { Share }\end{array}$ & $\begin{array}{l}\text { A non-voluntary response. Instructor calls randomly on a } \\
\text { group after they discuss a posed question. }\end{array}$ \\
\hline \multirow{5}{*}{$\begin{array}{l}\text { Volunteer } \\
\text { response }\end{array}$} & $\begin{array}{l}\text { Individual } \\
\text { volunteer response }\end{array}$ & $\begin{array}{l}\text { A voluntary response. Instructor poses a question and an } \\
\text { individual raises their hand to answer without conferring with } \\
\text { their group. }\end{array}$ \\
\cline { 2 - 3 } & $\begin{array}{l}\text { Volunteer response } \\
\text { Sost-Think Pair }\end{array}$ & $\begin{array}{l}\text { A voluntary response. Instructor poses a question, students } \\
\text { confer, and a student answers the question. }\end{array}$ \\
\hline $\begin{array}{l}\text { Volunteer response } \\
\text { post-Think Pair } \\
\text { Share and iclicker }\end{array}$ & $\begin{array}{l}\text { A voluntary response. Instructor poses a question, students } \\
\text { confer, students answer question using an iclicker, and a } \\
\text { student answers the question (either after the instructor shows } \\
\text { the answer or before). The difference between this response } \\
\text { and the 'post-TPS' response (above) is in this scenario, } \\
\text { students have committed to an answer before responding. }\end{array}$ \\
\hline
\end{tabular}

Table 1. In-class observers scored student-instructor interactions using five different categories. We use the term Think Pair Share to describe when an instructor poses a question, allows for students to discuss the question with their group or with a partner, and then calls on a group to share their answer. The term iclicker describes any personal response system that students use after the instructor poses a multiplechoice question on the overhead projector. Students use iclickers to 'vote' for which answer they think is correct (A, B, C, or D). We pool these five characterizations into either 'spontaneous question or comment' or 'volunteer response' for purposes of analyses.

\subsection{Statistical analysis}

We ran analyses separately for each type of student-instructor interaction (spontaneous question or comment and volunteer response) and all combined interactions for each class. Because Biology 102 is taught in two different sections one week apart, we analysed those classes separately (Biology 102A and Biology 102B). To assess whether there are gendered patterns in response to each interaction type, we employed a one-sample t-test to examine whether the proportion of female interactions in a class is more or less than one would expect (given the number of women in the class) in each type of interaction individually, and then all interactions combined. We used SPSS version 24 to conduct all statistical analyses.

\section{RESULTS}

In Fall 2016, we observed 89 interactions in Biology 100 across six class periods; in Biology 102A we observed 37 interactions across three class periods and for 102B we observed 38 interactions across 
three class periods. In Biology 100 there were 102 women and 75 men in the classroom, and we did not find a significant difference between the amount of women enrolled in the class $(58 \%)$ and the number of questions asked or comments made spontaneously (i.e. without being prompted by the instructor) by females (14 out of $24 ; t(23)=-0.03$, 2-tailed $p=0.974)$. However, the number of volunteer responses attributed to females (20 out of 65 ) was significantly lower $(t(64)=4.72, \mathrm{p}<$ $0.0001)$ than would be expected based on the number of females in the classroom. In other words, when the instructor posed a question directed at students, women were less likely to raise their hand with an answer than men. Combined, the total number of women who spoke in the classroom across the observed class periods was significantly lower than expected based on the women who were in the classroom (34 out of $89 ; t(88)=3.82, p<0.0001$; Figure 1 ).

In Biology 102A there were 22 women and 24 men who participated on the first week of the field course; there were 27 women and 17 men who were present the second week of the field course. For Biology 102A we did not find a significant difference between the amount of women enrolled in the class $(47 \%)$ and the number of spontaneous questions asked or comments made by females ( 7 out of $10 ; \mathrm{t}(9)=-1.51,2$-tailed $p=0.166)$ or the number of volunteer responses attributed to females (12 out of 27; $\mathrm{t}(26)=0.26,2$-tailed $p=0.795$. When we combined these values, the total number of women who spoke during that section of the field course across observations approximately matched the proportion of women who were present (19 out of 37; $\mathrm{t}(36)=-0.52$, 2-tailed $p=0.605$; Figure 1 ). In Biology 102B we only observed three instances of spontaneous comments and questions, and so we do not report the analysis here. However, we did find a significant difference between the amount of women enrolled in the class $(61 \%)$ and the number of voluntary responses made by females (14 out of $35 ; \mathrm{t}(34)=2.50$, 2-tailed $p=0.017$ ). Combined, the total number of women who spoke in whole-class discussions across the observed classes during the second part of the field course was significantly lower than expected based on the women who were on the course (16 out of $38 ; \mathrm{t}(37)=2.33$, 2-tailed $p$ $=0.025 ;$ Figure 1$)$.

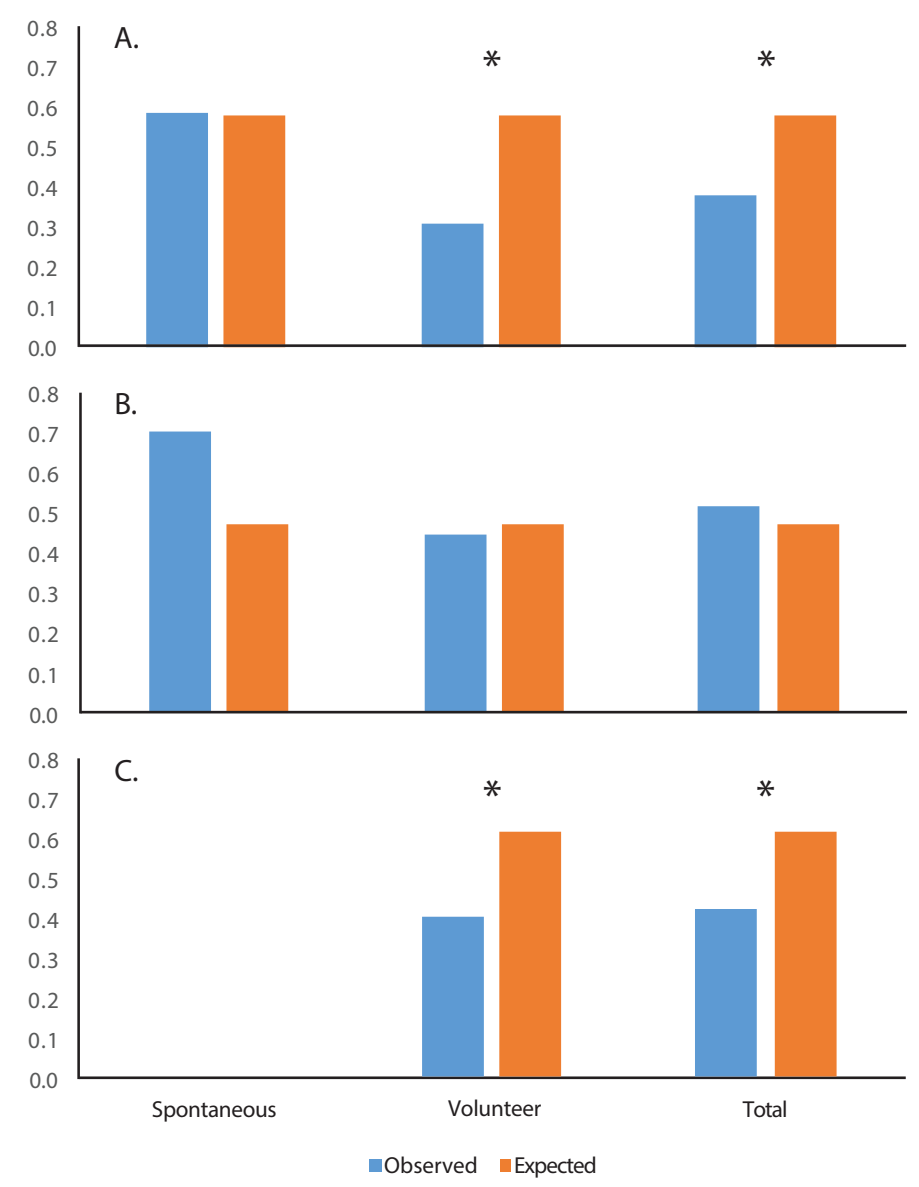

Figure 1. Contrasts of observed (blue bars) and expected (orange bars) proportions of female participants in whole-classroom discussions in three introductory biology courses: A) Biology 100, B) Biology 102A, and 
C) Biology 102B. We show data on students' spontaneous comments or questions, volunteer responses, and the total proportion of interactions between a student and instructor that are female. In panels A and C females contributed significantly less than would be expected given the proportion of women in the class, and we found no difference between observed and expected female participants in panel B. Note missing columns in panel $\mathrm{C}$ are due to insufficient in-class observations. ${ }^{*} \mathrm{p}<0.05$

\section{DISCUSSION}

We examined whether gender biased participation occurs in two large Norwegian biology courses, which take place in two drastically different settings: in a large traditional lecture theater in Bergen and a remote field setting. We found that in two out of three classes, females in whole-class discussions participated less frequently than would be expected based on the gender composition of the classes. We did not find any examples of gender bias reversals, where women spoke significantly more than men. Conclusions from the current study have several limitations. First, observers only evaluated a subset of all class periods, and so future semesters of observation, both at University of Bergen and elsewhere, will be required to generate a robust dataset in order to test the generality of these effects in undergraduate biology across Norway. Second, we do not document performance gaps (grades) in these classes, and encourage future research to focus on this performance outcome as a factor that contributes to observed female attrition. Our findings support the only previous study that examines participation and gender in an undergraduate STEM classroom (24) by demonstrating gender disparities in participation in whole-class discussions in biology. It also supports additional survey data in the United States from female students in biology, engineering, and chemistry courses who also self-report lower participation rates (31). Other studies across disciplines show conflicting results (31$33)$, and findings will likely vary across classroom environments based on instructor gender $(7,33)$, pedagogy $(34,35)$, discipline $(13,14,36)$, and in-class group dynamics $(15,37,38)$.

Our results suggest that in Norway, like the United States, women's voices are underrepresented in the classroom. Thus, we are the first study to suggest that despite a relatively gender equal society, women still face similar academic challenges as women elsewhere in the world. Future research will profit from a thorough examination of whether male students outperform females in other metrics of success at the undergraduate level in Norway, and whether there are lasting consequences. Research may also focus on underlying mechanisms that lead to observed gaps in participation. In the United States, one common explanation is stereotype threat, or the fear of conforming to a negative stereotype associated with one's social, racial, ethnic, or gender group $(6,39$ 41). For example, females tend to underestimate their math ability and overestimate how much ability is required to succeed at higher levels (42). Males, on the other hand, overestimate their math ability to be higher than comparable females' ability (42). And even subtle priming can reduce females' math performance in a test-taking environment. When asked to identify their gender before starting the SAT Advanced Calculus test, females score significantly lower than their female peers who are asked to check the gender box after the test $(43,44)$.

A multitude of documented approaches effectively reduce threat and create more inclusive environments for historically underrepresented students. Empirically validated interventions include the removal of cues that trigger stereotype threat (45-47), the use of positive role models (48-50), the use of values affirmation (51-54), and the emphasis on growth mindset theories about intelligence and achievement (55). Many of these interventions have been tested in controlled settings, external to the class environment, and many have yet to be applied in a large-scale, practical manner. Future research will benefit from integrating these interventions into introductory courses and quantifying their effects on metrics such as participation.

A significant gender gap in participation is a problem in the classroom. Those who speak in class exert larger influence on their peers, and the normalization of men speaking significantly more than women in science at the undergraduate level may influence what males and females consider 'normal' interaction between scientists farther along the academic pathway: in lab meetings as graduate students, at conferences as postdocs, and in departmental seminars as faculty. The causes and consequences of this demonstrated gap will require further investigation, but may have lasting impacts on females' scientific identity and long-term decision to remain in science.

\section{Acknowledgements}


We thank Iselin Partee for help with data collection; Oddfrid T. Kårstad Førland, Vigdis Vandvik, and Lucas Jeno for additional support. This research was approved by NSD Prosjektnr 46727, and funded by the Centre of Excellence in Biology Education (bioCEED) at University of Bergen and the Department of Biology Teaching and Learning at the University of Minnesota. Cissy Ballen was supported by a Research Council of Norway Mobility Grant (proposal no. 261529) awarded to S. Cotner. 


\section{References}

[1] Hedges, LV, and Nowell, A (1995), Sex differences in mental test scores, variability, and numbers of high-scoring individuals, Science, Vol. 269, No. 5220, pp. 41.

[2] Kimura, D (2000), Sex and cognition, (MIT press). $230 \mathrm{pp}$

[3] Hall, RM, and Sandler, BR (1982) The Classroom Climate: A Chilly One for Women? in Washington, DC: Project on the Status and Education of Women, Association of American Colleges.

[4] Guiso, L, Monte, F, Sapienza, P, and Zingales, L (2008), Culture, gender, and math, Science, Vol. 320, No. 5880, pp. 1164.

[5] Córdova, FA (2016), Intentional equity, Science, Vol. 353, No. 6298, pp. 427.

[6] Nosek, BA, et al. (2009), National differences in gender-science stereotypes predict national sex differences in science and math achievement, Proceedings of the National Academy of Sciences, Vol. 106, No. 26, pp. 10593-10597.

[7] Cotner, S, Ballen, C, Brooks, DC, and Moore, R (2011), Instructor gender and student confidence in the sciences: a need for more role models, Journal of College Science Teaching, Vol. 40, No. 5, pp. 96-101.

[8] Johnson, DR (2012), Campus racial climate perceptions and overall sense of belonging among racially diverse women in STEM majors, Journal of College Student Development, Vol. 53, No. 2, pp. 336-346.

[9] Espinosa, L (2011), Pipelines and pathways: Women of color in undergraduate STEM majors and the college experiences that contribute to persistence, Harvard

Educational Review, Vol. 81, No. 2, pp. 209-241.

[10] Fennema, E, and Peterson, PL (1985), Autonomous learning behavior: A possible explanation of sex-related differences in mathematics, Educational Studies in Mathematics, Vol. 16, No. 3, pp. 309-311.

[11] Clance, PR (1985), The impostor phenomenon: Overcoming the fear that haunts your success, (Peachtree Pub Ltd).

[12] Newsome, JL (2008), The chemistry PhD: The impact on women's retention, A report for the UK Resource Centre for Women in SET and the Royal Society of Chemistry, pp. 1-38.

[13] Beede, D, et al. (2011), Women in STEM: A Gender Gap to Innovation, Economics and Statistics Administration Issue Brief, Vol. 4, No. 11, pp. 1-11.

[14] Larivière, V, Chaoqun Ni, YG, Cronin, B, and Sugimoto, CR (2013), Global gender disparities in science, Nature, Vol. 504, No. 7479, pp. 211-213.

[15] Grunspan, DZ, et al. (2016), Males under-estimate academic performance of their female peers in undergraduate biology classrooms, PLoS ONE, Vol. 11, No. 2, pp. 116.

[16] Moss-Racusin, CA, Dovidio, JF, Brescoll, VL, Graham, MJ, and Handelsman, J (2012), Science faculty's subtle gender biases favor male students, Proceedings of the National Academy of Sciences, Vol. 109, No. 41, pp. 16474-16479.

[17] Greenwald, AG, and Krieger, LH (2006), Implicit bias: scientific foundations, California Law Review, Vol. 94, No. 4, pp. 945-967.

[18] Ceci, SJ, Ginther, DK, Kahn, S, and Williams, WM (2014), Women in academic science A changing landscape, Psychological Science in the Public Interest, Vol. 15, No. 3, pp. 75-141.

[19] Sheltzer, JM, and Smith, JC (2014), Elite male faculty in the life sciences employ fewer women, Proceedings of the National Academy of Sciences, Vol. 111, No. 28, pp. 10107-10112.

[20] Young, DM, Rudman, LA, Buettner, HM, and McLean, MC (2013), The influence of female role models on women's implicit science cognitions, Psychology of Women Quarterly, Vol. 37, No. 3, pp. 283-292. 
[21] Haley, MR, Johnson, MF, and Kuennen, EW (2007), Student and professor gender effects in introductory business statistics, Journal of Statistics Education, Vol. 15, No. pp. 1-19.

[22] Hoffmann, F, and Oreopoulos, P (2009), A professor like me: the influence of instructor gender on college achievement, Journal of Human Resources, Vol. 44, No. 2, pp. 479-494.

[23] Carrell, SE, Page, ME, and West, JE (2009) Sex and science: How professor gender perpetuates the gender gap. National Bureau of Economic Research, No. 14959.

[24] Eddy, SL, Brownell, SE, and Wenderoth, MP (2014), Gender gaps in achievement and participation in multiple introductory biology classrooms, CBE-Life Sciences Education, Vol. 13, No. 3, pp. 478-492.

[25] Griffith, AL (2010), Persistence of women and minorities in STEM field majors: Is it the school that matters?, Economics of Education Review, Vol. 29, No. 6, pp. 911-922.

[26] Luckenbill-Edds, L (2002), The educational pipeline for women in biology: No longer leaking?, Bioscience, Vol. 52, No. 6, pp. 513-521.

[27] Amelink, C (2009), Literature overview: Gender differences in science achievement, Society of Women Engineers - Assessing Women \& Men in Engineering Center for Advancement of Scholarship in Engineering Education Overviews, pp 1-22.

[28] Handelsman, J, et al. (2005), More women in science, Science, Vol. 309, No. 5738, pp. 1190-1191.

[29] Beede, DN, et al. (2011), Women in STEM: A gender gap to innovation, Economics and Statistics Administration Issue Brief, No. 04-11, pp. 1-11.

[30] Hole, TN, et al. (2016) bioCEED Survey 2015 (Retrieved from University of Bergen, Bora - Bergen Open Research Archive: http://hdl.handle.net/1956/11952).

[31] Crombie, G, Pyke, SW, Silverthorn, N, Jones, A, and Piccinin, S (2003), Students' perceptions of their classroom participation and instructor as a function of gender and context, The journal of higher education, Vol. 74, No. 1, pp. 51-76.

[32] Howard, JR, and Henney, AL (1998), Student participation and instructor gender in the mixed-age college classroom, Journal of Higher Education, Vol. No. pp. 384405.

[33] Cornelius, RR, Gray, JM, and Constantinople, AP (1990), Student-faculty interaction in the college classroom, Journal of Research \& Development in Education.

[34] Shackelford, J (1992), Feminist pedagogy: A means for bringing critical thinking and creativity to the economics classroom, The American Economic Review, Vol. 82, No. 2, pp. 570-576.

[35] Rodriguez, I, Potvin, G, and Kramer, LH (2016), How gender and reformed introductory physics impacts student success in advanced physics courses and continuation in the physics major, Physical Review Physics Education Research, Vol. 12, No. 2, pp. 020118.

[36] Cheryan, S, Ziegler, SA, Montoya, AK, and Jiang, L (2016), Why Are Some STEM Fields More Gender Balanced Than Others?, Psychological Bulletin, Vol. 143, No. 1, pp. 1-35.

[37] Lemoine, GJ, Aggarwal, I, and Steed, LB (2016), When women emerge as leaders: Effects of extraversion and gender composition in groups, The Leadership Quarterly, Vol. 27, No. 3, pp. 470-486.

[38] West, TV, Heilman, ME, Gullett, L, Moss-Racusin, CA, and Magee, JC (2012), Building blocks of bias: Gender composition predicts male and female group members' evaluations of each other and the group, Journal of Experimental Social Psychology, Vol. 48, No. 5, pp. 1209-1212.

[39] Lauer, S, et al. (2013), Stereotyped: investigating gender in introductory science courses, CBE-Life Sciences Education, Vol. 12, No. 1, pp. 30-38. 
[40] McGlone, MS, Aronson, J, and Kobrynowicz, D (2006), Stereotype threat and the gender gap in political knowledge, Psychology of Women Quarterly, Vol. 30, No. 4, pp. 392-398.

[41] Schmader, T (2002), Gender identification moderates stereotype threat effects on women's math performance, Journal of Experimental Social Psychology, Vol. 38, No. 2, pp. 194-201.

[42] Correll, SJ (2004), Constraints into preferences: Gender, status, and emerging career aspirations, American sociological review, Vol. 69, No. 1, pp. 93-113.

[43] Stricker, LJ, and Ward, WC (2004), Stereotype Threat, inquiring about test takers' ethnicity and gender, and standardized test performance, Journal of Applied Social Psychology, Vol. 34, No. 4, pp. 665-693.

[44] Stricker, LJ, and Ward, WC (2008), Stereotype threat in applied settings re-examined: a reply, Journal of Applied Social Psychology, Vol. 38, No. 6, pp. 1656-1663.

[45] Cheryan, S, Plaut, VC, Davies, PG, and Steele, CM (2009), Ambient belonging: how stereotypical cues impact gender participation in computer science, Journal of Personality and Social Psychology, Vol. 97, No. 6, pp. 1045.

[46] Danaher, K, and Crandall, CS (2008), Stereotype threat in applied settings reexamined, Journal of Applied Social Psychology, Vol. 38, No. 6, pp. 1639-1655.

[47] Steele, CM, and Aronson, J (1995), Stereotype threat and the intellectual test performance of African Americans, Journal of Personality and Social Psychology, Vol. 69, No. 5, pp. 797-811.

[48] Marx, DM, and Goff, PA (2005), Clearing the air: The effect of experimenter race on target's test performance and subjective experience, British Journal of Social Psychology, Vol. 44, No. 4, pp. 645-657.

[49] Marx, DM, and Roman, JS (2002), Female role models: Protecting women's math test performance, Personality and Social Psychology Bulletin, Vol. 28, No. 9, pp. 11831193.

[50] McIntyre, RB, Paulson, RM, and Lord, CG (2003), Alleviating women's mathematics stereotype threat through salience of group achievements, Journal of Experimental Social Psychology, Vol. 39, No. 1, pp. 83-90.

[51] Cohen, GL, Garcia, J, Apfel, N, and Master, A (2006), Reducing the racial achievement gap: A social-psychological intervention, Science, Vol. 313, No. 5791, pp. 1307-1310.

[52] Cohen, GL, Garcia, J, Purdie-Vaughns, V, Apfel, N, and Brzustoski, P (2009), Recursive processes in self-affirmation: Intervening to close the minority achievement gap, Science, Vol. 324, No. 5925, pp. 400-403.

[53] Martens, A, Johns, M, Greenberg, J, and Schimel, J (2006), Combating stereotype threat: The effect of self-affirmation on women's intellectual performance, Journal of Experimental Social Psychology, Vol. 42, No. 2, pp. 236-243.

[54] Miyake, A, et al. (2010), Reducing the gender achievement gap in college science: A classroom study of values affirmation, Science, Vol. 330, No. 6008, pp. 1234-1237.

[55] Yeager, DS, and Dweck, CS (2012), Mindsets that promote resilience: when students believe that personal characteristics can be developed, Educational Psychologist, Vol. 47, No. 4, pp. 302-314. 